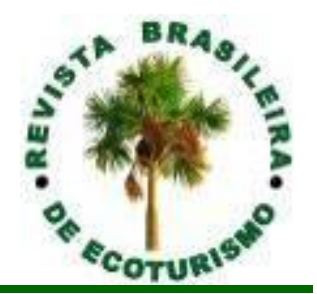

\title{
Ecoturismo no Pós-COVID-19 no Parque Nacional da Tijuca e Parque Estadual da Pedra Branca
}

\section{Ecotourism in Post-COVID-19 in Tijuca National Park and Pedra Branca State Park}

Rodrigo Machado Vilani, Roberta Campelo Pena, Bruno Francisco Teixeira Simões

\begin{abstract}
RESUMO: A pandemia da COVID-19 exige uma revisão de parâmetros e hábitos individuais, coletivos e institucionais. O turismo é um dos setores econômicos mais afetados pelas medidas adotadas em todo planeta diante da pandemia. $O$ presente artigo tem por objetivo discutir a retomada das atividades de ecoturismo em duas unidades de conservação no Rio de Janeiro (Parque Nacional da Tijuca e Parque Estadual da Pedra Branca). A pesquisa foi desenvolvida por meio de revisão bibliográfica e análise de documentos oficiais. Os resultados obtidos revelam a importância do ecoturismo como alternativa econômica para iniciativas comunitárias e a falta de recursos humanos e financeiros como obstáculos à segurança sanitária em unidades de conservação. As diretrizes básicas para o fortalecimento do ecoturismo pós-pandemia são: a) garantir segurança sanitária em unidades de conservação e seu entorno; b) produzir e disseminar evidências científicas sobre iniciativas locais de ecoturismo, uso público e saneamento em unidades de conservação; c) contribuir para a elaboração de políticas públicas (ambientais, sociais e de saneamento); d) desenvolver o ecoturismo em parques urbanos; e) reduzir as desigualdades sociais por meio do ecoturismo; f) estimular uma reflexão crítica acerca do potencial do ecoturismo como alternativa econômica para comunidades em situação de vulnerabilidade social e ambiental.
\end{abstract}

PALAVRAS-CHAVE: Visitação; Parques Urbanos; Plano de Manejo; Plano de Uso Público.

ABSTRACT: The COVID-19 pandemic requires a review of individual, collective and institutional parameters, and habits. Tourism is one of the economic sectors most affected by the measures adopted across the planet because of the pandemic. The aim of this study is to discuss the resumption of ecotourism activities in two protected areas in Rio de Janeiro (Tijuca National Park and Pedra Branca State Park). This research was developed by using bibliographic review and analysis of official documents. The result of this research reveals the importance of ecotourism as an economic alternative for community initiatives and the lack of human and financial resources as obstacles to health security in protected areas. The basic guidelines for strengthening post-pandemic ecotourism are: a) ensuring health security in protected areas and their surroundings; b) produce and disseminate scientific evidence on local ecotourism, public use and sanitation initiatives in protected areas; c) contribute to the elaboration of public policies (environmental, social and sanitation); d) develop ecotourism in urban parks; e) reduce social inequalities through ecotourism; f) encourage critical reflection on the potential of ecotourism as an economic alternative for communities in situations of social and environmental vulnerability.

KEYWORDS: Visitation; Urban Parks; Management Plan; Public Use Plan. 


\section{Introdução}

Em dezembro de 2019 foram reportados os primeiros casos da doença COVID-19 em pacientes epidemiologicamente ligados ao mercado de frutos do mar de Wuhan, na China (ROTHAN; BYRAREDDY, 2020). Em 9 de junho de 2020, segundo dados da Organização Mundial de Saúde (WHO, 2020) eram 7.039.918 de casos confirmados e 404.396 mortes nos 216 países alcançados pela COVID-19. Na mesma data, no Brasil, foram confirmados 691.758 casos e 36.455 mortes (WHO, 2020).

Ao analisar a pandemia, Harvey (2020) acentua que as modificações causadas ao meio ambiente pelo capital não configuram um desastre natural. $O$ autor afirma que "as circunstâncias nas quais uma mutação [dos vírus] se torna uma ameaça à vida dependem das ações humanas" (HARVEY, 2020, p. 15) e seus impactos são resultantes das "fissuras e vulnerabilidades preexistentes no modelo econômico hegemônico" (HARVEY, 2020, p. 16). No mesmo sentido, Žižek (2020 p. 44) trata a pandemia como "um sinal de que não podemos continuar no caminho em que temos estado até agora, de que é necessária uma mudança radical". Os impactos da pandemia da COVID-19, causada pelo coronavírus SARS-CoV-2, indicam, portanto, a necessidade de revisão do crescimento capitalista, de maneira geral, e, especificamente, do turismo de massa.

Apesar da vestimenta utópica aplicada às reflexões e iniciativas de natureza contra-hegemônica, Everingham e Chassagne (2020) criticam as estruturas neocoloniais que determinam as sociedades e as iniquidades do capitalismo neoliberal, especialmente no Sul Global, aplicando um repertório crítico assentado nas reflexões de Quijano (2000) e Acosta (2016) entre outros.

Para a análise do tema, em consonância com as reflexões críticas ao capitalismo, entende-se ecoturismo como fenômeno "transformador e incompatível com a mercantilização da natureza e do patrimônio cultural" e que "deve ser estudado, estimulado e praticado como um fenômeno de ruptura e resistência, cuja essência é o respeito aos tempos e aos ciclos naturais e dos povos e comunidades tradicionais" (VILANI, 2018, p. 618).

Defende-se aqui a construção de uma alternativa ao modelo capitalistacolonial a partir de uma transição para uma economia pós-extrativista ou póscapitalista estruturada sobre o desenvolvimento de atividades sustentáveis como 0 (eco)turismo (ACOSTA, 2016; LANG; 2016; GUDYNAS, 2016).

Logo, a partir da conjuntura mundial e das incertezas quanto à retomada das atividades econômicas e da rotina social pós-pandemia da COVID-19 o presente artigo tem por objetivo discutir a retomada do ecoturismo em duas unidades de conservação localizadas no município do Rio de Janeiro, o Parque Nacional da Tijuca e o Parque Estadual da Pedra Branca.

A reflexão proposta, portanto, parte dos planos de manejo (PM) desses parques e do seu contexto urbano. O PM é um documento elaborado a partir de diversos estudos, o qual estabelece as normas, restrições para o uso, ações a serem desenvolvidas e manejo dos recursos naturais da UC. O PM, principal instrumento da gestão das UCs, é definido legalmente como: 
o documento técnico mediante o qual, com fundamento nos objetivos gerais de uma UC, se estabelece o seu zoneamento e as normas que devem presidir o uso da área e o manejo dos recursos naturais, inclusive a implantação das estruturas físicas necessárias à gestão da unidade (BRASIL, 2000).

Quais serão as diretrizes para o uso público das UCs pós-pandemia e qual o papel do PM nesse cenário futuro?

A pandemia da COVID-19 desencadeou uma "imobilidade global" (IOANNIDES; GYIMÓTHY, 2020, p. 2) e, mesmo diante das incertezas ainda existentes, demandou um processo de mudanças nos padrões de mobilidade, socialização, consumo, lazer e trabalho (ROMAGOSA, 2020; EVERINGHAM, CHASSAGNE, 2020) que tiveram e terão repercussões importantes nos diversos segmentos de turismo. Fletcher et al. (2020) apontam que voltar aos padrões de turismo anteriores à COVID-19 é um luxo que não pode ser retomado, mesmo pelos grupos mais privilegiados economicamente, devido aos impactos sociais e ambientais do overtourism 1 .

No Brasil, segundo estimativas produzidas pela Fundação Getúlio Vargas (FGV, 2020, p. 11):

As perdas econômicas do setor, em comparação ao PIB do setor em 2019 , serão significativas. Considerando os volumes de produção [de 2019] o PIB do setor será de $R \$ 165,5$ bilhões em 2020 (redução de $38,9 \%$ em relação à 2019) e $R \$ 259,4$ bilhões em 2021 (próximo de retomar o patamar de 2019, porém ainda 4,2\% inferior). Dessa forma, a perda total do setor turístico brasileiro será de $R \$ 116,7$ bilhões no biênio 2020-2021 (que representa perda de $21,5 \%$ na produção total do período).

A multissetorialidade do turismo amplifica os impactos e repercute sobre hospedagens, bares e restaurantes, transportes, agências e os trabalhadores do setor, entre outros (FGV, 2020).

A partir dessa conjuntura, a pesquisa está assentada sobre a realidade do município do Rio de Janeiro, onde está localizado o Parque Nacional da Tijuca (PNT), UC com maior índice de visitação no País. Em 2018, segundo dados do ICMBio (2019), foram 12,4 milhões de visitas a UCs federais, das quais 2,6 milhões foram ao PNT, 1,89 milhão ao Parque Nacional do Iguaçu (PR) e 1,09 milhão de visitas ao Parque Nacional de Jericoacoara (CE). O Parque Estadual da Pedra Branca (PEPB), também localizado no município do Rio de Janeiro, merece destaque em razão da sua importância enquanto um dos mais importantes remanescentes de Mata Atlântica no Brasil (VILANI; COELHO, 2017), visto abranger uma área de cerca de 12.500 hectares, que corresponde a cerca de $10 \%$ do território municipal, que levou o PEPB a ser reconhecido na década de 2000', como a maior floresta urbana do planeta (FERNANDEZ, 2011).

Ao analisar a realidade socioeconômica do Rio de Janeiro, em especial do entorno do PNT e do PEPB, caracterizado por bairros e favelas com altos índices de desemprego e criminalidade e baixa renda per capita, Peixoto e Irving (2019) defendem a integração das UCs com as comunidades para o bem-estar da população do entorno, visitantes e (ecoturistas) para a construção dos Parques da 
Paz, conceito que insere na categoria parque "um valor simbólico ampliado e se internaliza no imaginário não apenas como possibilidade de lazer e contato com a natureza, mas também como elemento central de qualidade de vida e dignidade para o cidadão urbano" (PEIXOTO; IRVING, 2013, p. 30).

Uma vez que a transmissão da COVID-19 está relacionada, entre outras, às condições de saneamento, cumpre destacar que, segundo o PM do PNT, em relação às moradias existentes dentro dos limites do parque, "o maior problema seja o de contaminação do solo e da água subterrânea, pela falta de infraestrutura adequada de saneamento em toda a área do Parque Nacional da Tijuca, inclusive na administração" (ICMBio, 2008, p. 217).

A releitura do papel e importância dos parques em grandes centros urbanos faz-se urgente diante da conjuntura imposta pela pandemia da COVID-19 e, por desdobramento, são necessários esforços teórico-metodológicos no campo do ecoturismo e das políticas públicas - sociais, de saneamento e saúde, e de conservação da natureza.

O presente artigo está, portanto, estruturado de forma a trazer elementos de reflexão quanto à capacidade institucional de organizar e de avaliar as ações para minimizar os riscos à saúde durante a visitação.

\section{Material e métodos}

A opção metodológica foi por uma pesquisa exploratória com o objetivo de proporcionar maior familiaridade com o tema, a fim de torná-lo mais explícito (GIL, 2002), diante da atualidade e das incertezas sobre a retomada das atividades turísticas. O presente trabalho é resultado de uma pesquisa realizada em dois momentos distintos: a) 2018: levantamento voltado para planos de manejo no Brasil; b) 2020: documentos e estudos específicos sobre a relação entre ecoturismo e a COVID-19.

A pesquisa foi dividida em duas etapas, (i) Levantamento bibliográfico; (ii) Análise de documentos, conforme descrito a seguir:

Etapa 1: Levantamento bibliográfico, que foi realizado em dois momentos:

a. Estado da arte sobre planos de manejo foi realizado a partir da revisão bibliográfica, realizada entre outubro de 2016 a março de 2018, de textos e artigos relacionados com o tema. Além das pesquisas realizadas diretamente nos sites institucionais dos órgãos ambientais (ICMBio e INEA), utilizou-se a base de dados do Periódico Capes, Scielo, Pub Med e Biblioteca Digital Brasileira de Teses e Dissertações, com a combinação das seguintes palavras-chave em português e inglês: (i) Plano de Manejo; (ii) Monitoramento; (iii) Avaliação; (iv) UC; (v) Implementação; (vi) Análise; (vii) Efetividade.

b. em razão da atualidade do tema, para a pesquisa quanto à ecoturismo e COVID-19 foi consultada também a base Google Scholar. Os resultados encontrados foram selecionados a partir da aderência com a pesquisa, determinada, inicialmente, por meio da leitura dos títulos e resumos.

Etapa 2: Análise dos documentos, onde foram priorizados documentos oficiais como: i. Roteiros Metodológicos para elaboração de Planos de Manejo do ICMBio e INEA; ii. Orientações metodológicas para elaboração de Planos de Uso Público do ICMBio; iii. Roteiro para manejo de impactos da visitação; iv. PM do PNT e PEPB; v. Portarias o ICMBio n. 696 e 697 de 2020; vi. outras publicações oficiais. 
Dentre os roteiros metodológicos foram analisados os dois principais roteiros para UCs de proteção integral. São eles: i. Roteiro Metodológico de Planejamento: Parque Nacional, Reserva Biológica e Estação Ecológica (IBAMA, 2002); ii. Roteiro Metodológico para Elaboração de PM: Parques Estaduais, Reservas Biológicas, Estações Ecológicas (INEA, 2010).

\section{Manejo e uso público de UCs no Brasil}

O manejo e o uso público das UCs são definidos tecnicamente, portanto, possuem embasamento técnico-científico para a definição, entre outros, das diretrizes para o zoneamento, das normas referentes ao manejo dos recursos naturais, das estruturas físicas a serem implantadas e da capacidade de carga de visitação.

Por desdobramento, entende-se que a elaboração dos planos de manejo e de uso público devem ser orientadas pelo princípio da precaução. Aragão $(2010$, p. 9) ressalta "que o princípio da precaução pressupõe uma avaliação científica dos aspectos testáveis e verificáveis do risco antes da adopção de qualquer medida" e conclui que "as medidas são tomadas por causa dos dados científicos, e não à revelia da ciência; mantêm-se em vigor em virtude dos dados científicos, e não contra eles" (2010, p. 10).

A perspectiva da precaução é destacada em relação à da prevenção diante do grau de incerteza que envolve o contexto da pandemia da COVID-19. A certeza científica tomada como elemento do nexo de causalidade coloca a prevenção aplicada ao risco certo e, por outro lado, a precaução direcionada ao risco abstrato (CARVALHO, 2008; VARELLA; PLATIAU, 2004). A título de exemplificação, a obra Primavera Silenciosa pode ser considerada um marco na aplicação da precaução, visto que, ainda na década 1960 , estabelece uma relação potencial entre as substâncias químicas e a degradação da natureza e, diante desta, afirma a necessidade de uma "investigação prévia de seu efeito sobre o solo, a água, os animais selvagens e os próprios seres humanos" (CARSON, 2010, p. 28).

A precaução justifica-se diante da constatação de Barreto et al. (2020):

O insuficiente conhecimento científico sobre o novo coronavírus, sua alta velocidade de disseminação e capacidade de provocar mortes em populações vulneráveis geram incertezas quanto à escolha das melhores estratégias a serem utilizadas para o enfrentamento da epidemia em diferentes partes do mundo. No Brasil, os desafios que se apresentam são ainda maiores, pois pouco se sabe sobre as características de transmissão da Covid-19 num contexto de grande desigualdade social e demográfica, com populações vivendo em condições precárias de habitação e saneamento, sem acesso constante à água, em situação de aglomeração e com alta prevalência de doenças crônicas.

No contexto da COVID-19, portanto, pode ser adotada a classificação de Aragão (2013, p. 12) quanto às incertezas científicas: i. ontológica: parte da complexidade dos ecossistemas e, no caso em estudo, da dinâmica do novo coronavírus; ii. epistemológica: aplicada quando há "inexistência, inadequação ou incompletude dos dados [...]", como no momento de pesquisas para melhor compreensão e descrição de ação do SARS-CoV-2; iii. hermenêutica: representa as 
"diferentes interpretações da realidade e, portanto, diferentes visões quanto à importância do risco", observada no cenário nacional diante das distintas percepções de ação no âmbito do governo federal que, inclusive, definiram a demissão de dois Ministros da Saúde.

Dessa forma,

O presidente da república conseguiu paralisar o Ministério da Saúde que não está exercendo o papel que lhe cabe, como gestor federal do SUS, de coordenação do esforço para controlar a epidemia. Ao revés, dificulta repasses orçamentários para a rede de estados e municípios, não auxilia a aquisição de testes e equipamentos, por vezes, atrapalha, além de enfraquecer as diretrizes para 0 isolamento social. Até os hospitais federais do Rio de Janeiro tiveram que ser constrangidos pelo judiciário a reconhecer que havia uma epidemia grave (CAMPOS, 2020, p. 4).

O Presidente da República, contudo, tem contrariado as premissas da precaução. Adotou uma postura negacionista ao disseminar informações sem comprovação científica quanto a sintomas, riscos e curas da COVID-19 e instigar e participar de aglomerações. Por outro lado, sustenta discurso economicista por meio do qual se exime da responsabilidade pela recessão econômica pós-pandemia e cria um ônus político para governadores e prefeitos (RICARD; MEDEIROS, 2020).

A postura do Chefe do Executivo Federal, portanto, indica que uma reorientação espontânea é o principal obstáculo para pensar políticas orientadas socioambientalmente no pós-pandemia. Contudo, iniciativas e mobilizações de diversos coletivos - sociais, profissionais e científicos - foram exitosas no combate à desinformação do discurso presidencial (CAMPOS, 2020). Assim sendo, a premissa da cautela antecipada será um elemento estruturante da presente análise e para a elaboração de propostas gerais que visam contribuir para 0 debate $e$ fortalecimento das políticas de gestão, manejo e uso público de UCs.

\section{Obstáculos à gestão das UCs}

Schiavetti et al. (2012) identificam o PM como instrumento fundamental para efetividade da gestão das UCs. Entretanto, historicamente, grande parte das UCs brasileiras não implementaram tal instrumento. Em 1999, das 86 UCs federais de uso indireto com mais de seis anos de criação, 55\% estavam em situação precária, não oferecendo condições de cumprir com o papel para o qual foram criadas e a ausência de PM foi identificada como um dos principais problemas (LEMOS DE SÁ; FERREIRA, 2000).

$\mathrm{Na}$ esfera federal, os dados divulgados pelo ICMBio no $3^{\circ}$ Encontro de Parques de Montanha (MELLO, 2017) no Rio de Janeiro, apontam que apenas 53\% das UCs federais possuíam PM. Do total de 327 UC federais, 70 possuíam PM em elaboração, e outras 34 UC estavam com seus PM em revisão. No âmbito estadual, Pena (2018) identificou que Alagoas, Minas Gerais e Rio de Janeiro apresentaram resultado próximo ao das UCs federais com mais de $50 \%$ das UCs sem PM.

Essa realidade revela o problema de planejamento na gestão dessas áreas, que se traduz em um dos desafios a serem superados pelos órgãos gestores. Segundo Medeiros e Pereira (2011) problemas comuns na elaboração de PM no Brasil são: (i) Falta de recursos humanos; (ii) Descontinuidade e/ou ausência de 
gestão; (iii) Tempo destinado à coleta de dados; (iv) Recursos financeiros escassos; (v) Planejamentos interrompidos.

Estudo elaborado por Schiavetti et al. (2012) em trinta UCs de Mata Atlântica no estado da Bahia revela que a existência do PM não é suficiente para efetividade da gestão. Neste caso, $70 \%$ das UCs estudadas possuíam PM, ou estavam em fase de elaboração, e apenas $3,3 \%$ foram classificadas como satisfatoriamente implementadas. Schiavetti et al. (2012) apontam, além do PM, a necessidade de recursos humanos e financeiros, e infraestrutura básica como itens fundamentais para boa gestão de UCs.

Mello (2017) corrobora estes gargalos institucionais e destaca, no âmbito das dificuldades para implementação dos PM: (i) PM são muito operacionais e detalhados; (ii) Planejamento é muito rígido; (iii) Dinamismo no contexto das UC; (iv) Condições desfavoráveis de recursos humanos e orçamento; (v) Baixa sinergia com outros planejamentos institucionais; e (vi) Cultura institucional em relação aos PM.

Em levantamento realizado junto a gestores de 66 UCs distribuídas em dezoito estados brasileiros, Pena (2018) verificou que $68 \%$ das UCs pesquisadas possuíam PM, enquanto 18\% não haviam elaborado o PM e 14\% estavam com o documento em elaboração. Ao analisar as dificuldades na implementação do PM, Pena (2018) identificou aspectos institucionais (orçamentárias e recursos humanos) e técnicos (complexidade do PM e capacitação dos gestores) como causas para o PM não ter alcançado eficácia plena no âmbito da gestão das UCs.

\section{Epidemiologia da COVID-19 e o ecoturismo}

Os coronavírus em seres humanos podem resultar de doenças com sintomas comuns de gripe à chamada Síndrome Respiratória Aguda Grave, cuja sigla em inglês é SARS. Em 2002, o primeiro coronavírus a causar epidemia foi o Sars-CoV1, com início determinado em Guangzhou, China, alcançou 29 países. A Síndrome Respiratória do Oriente Médio (MERS), ocorrida em 2012, também foi causada por um coronavírus (LIMONGI; OLIVEIRA, 2020).

Abreu, Tejeda e Guach (2020) indicam que a COVID-19 possui transmissão pessoa a pessoa semelhante às outras doenças causadas por coronavírus, caracterizada por: i. contato com secreções de pessoas infectadas, principalmente por contato direto em distâncias inferiores a 2 metros; ii. por meio do contato com mãos ou fômites contaminados com estas secreções seguidas de contato com a mucosa boca, nariz ou olhos.

O ICMBio publicou as Portarias 696 e 697, respectivamente, em maio e junho de 2020, por meio das quais estabelece a reabertura dos parques nacionais de Aparados da Serra, da Serra Geral e do Iguaçu. As portarias indicam medidas de higienização e distanciamento entre os visitantes, bem como determinam o estabelecimento de medidas para promover a distribuição do número de visitantes ao longo do tempo e do espaço, tais como o agendamento do horário de entrada e a organização do fluxo dos grupos de visitantes, visando evitar aglomerações e/ou picos de visitação em determinados locais, dias ou horários. Nos parques nacionais de Aparados da Serra e da Serra Geral está definido um limite de $40 \%$ de sua capacidade de público e para o do Iguaçu de até $30 \%$ de forma que a visitação possa ocorrer respeitando-se o espaçamento mínimo de 2 metros entre as pessoas.

Mesmo diante das dificuldades institucionais das UCs e em meio à pandemia, o ICMBio facultou a reabertura dos parques a partir do início de junho, momento em 
que não havia evidência científica disponível acerca do pico de transmissão da COVID-19 no Brasil. Uma previsão, elaborada por uma plataforma de análise de dados de saúde no país (FUNCIONAL..., 2020), é de que o pico da pandemia seja em 6 de julho com 1,78 milhões de casos no Brasil. Nos dias 09 e 10 de junho, data prevista para início da reabertura dos parques, o Brasil teve 1.270 óbitos/dia pela COVID-19 (WHO, 2020).

Os dados da COVID-19 indicam uma flexibilização prematura no fechamento dos parques e, por desdobramento, uma exposição a riscos tanto de visitantes como de servidores públicos que contraria o princípio da precaução.

Para o fechamento da análise específica da COVID-19 "não se pode deixar de reconhecer que a pandemia, evidentemente, agravará algumas expressões da questão social, especialmente, o desemprego" (SOUZA, 2020, p. 2476). Portanto, é preciso definir ações e construir alternativas econômicas para o pós-pandemia de forma planejada, cientificamente embasada e inclusiva.

Nesse sentido, Botelho e Rodrigues (2016) defendem a necessidade de ações para o fortalecimento de iniciativas de base comunitária em parques nacionais. Qualificação profissional, ampliação de recursos financeiros, formação e treinamento de gestores de Unidades de Conservação e de lideranças locais, são ações propostas pelas autoras para o desenvolvimento do (eco)turismo em parques nacionais (BOTELHO; RODRIGUES, 2020, p. 293).

\section{Propostas de adequações nos planos de manejo e uso público}

Apesar dos obstáculos orçamentários, humanos e de infraestrutura indicados são necessários esforços de compreensão e contribuição para os planos de manejo e uso público e, por desdobramento, para a gestão das UCs. Logo, serão analisadas, primeiramente, as diretrizes para elaboração dos PM, contidas em roteiros metodológicos e, sem seguida, os documentos relativos a uso público e manejo dos impactos da visitação, conforme ordem cronológica indicada no Quadro 1.

Quadro 1: Linha do tempo - manejo e uso público em UCs.

Table 1: Timeline - management and public use in UCs.

\begin{tabular}{|l|c|c|}
\hline \multicolumn{1}{|c|}{ Documento } & Ano & $\begin{array}{c}\text { Órgão } \\
\text { responsável }\end{array}$ \\
\hline $\begin{array}{l}\text { Roteiro Metodológico de Planejamento: Parque Nacional, Reserva Biológica } \\
\text { e Estação Ecológica }\end{array}$ & 2002 & IBAMA \\
\hline $\begin{array}{l}\text { Roteiro Metodológico para Elaboração de Plano de Manejo para Florestas } \\
\text { Nacionais }\end{array}$ & 2003 & IBAMA \\
\hline $\begin{array}{l}\text { Roteiro Metodológico para Elaboração de Plano de Manejo para Reserva } \\
\text { Particular do Patrimônio Natural }\end{array}$ & 2004 & IBAMA \\
\hline $\begin{array}{l}\text { Roteiros Metodológicos: Plano de Manejo de Uso Múltiplo das Reservas } \\
\text { Extrativistas Federais }\end{array}$ & 2004 & IBAMA \\
\hline $\begin{array}{l}\text { Roteiro Metodológico para Elaboração de Plano de Manejo: Parques } \\
\text { Estaduais, Reservas Biológicas e Estações Ecológicas }\end{array}$ & 2010 & INEA \\
\hline $\begin{array}{l}\text { Roteiro metodológico para manejo de impactos da visitação com Enfoque na } \\
\text { Experiência do Visitante e na Proteção dos Recursos Naturais e Culturais }\end{array}$ & 2011 & ICMBio \\
\hline $\begin{array}{l}\text { Roteiro Metodológico Estadual para Elaboração de Plano de Manejo de } \\
\text { RPPN }\end{array}$ & 2012 & INEA \\
\hline $\begin{array}{l}\text { Roteiro metodológico para elaboração e revisão de planos de manejo das } \\
\text { unidades de conservação federais }\end{array}$ & 2018 & ICMBio \\
\hline $\begin{array}{l}\text { Orientações metodológicas para elaboração de planos de uso público em } \\
\text { unidades de conservação federais }\end{array}$ & 2019 & ICMBio \\
\hline
\end{tabular}

Fonte: Elaborado pelos autores. Source: Prepared by the authors. 
Foram selecionados os documentos (Quadro 1) publicados a partir da promulgação do SNUC, em 2000. O primeiro roteiro metodológico elaborado após o SNUC foi o 'Roteiro Metodológico de Planejamento: Parque Nacional, Reserva Biológica e Estação Ecológica', publicado em 2002, atualmente utilizado pelo órgão federal para elaboração de PM de UC de Proteção Integral, que representa um aprimoramento do roteiro de UC de Uso Indireto (MELLO, 2008). Outro roteiro também baseado no antigo roteiro de UC de Uso Indireto foi o Roteiro Metodológico para Elaboração de PM para Florestas Nacionais, publicado em 2003 (MELLO, 2008).

Em 2004, o IBAMA publicou mais dois roteiros, o Roteiro Metodológico para Elaboração de PM para Reserva Particular do Patrimônio Natural e Roteiros Metodológicos: PM de Uso Múltiplo das Reservas Extrativistas Federais.

Os roteiros metodológicos elaborados pelo IBAMA atendem não somente às UC federais, mas também as estaduais e municipais, o que de fato vem ocorrendo, seja utilizando o roteiro diretamente ou utilizando-os para desenvolver uma metodologia para os estados ou municípios (MELLO, 2008). Como realizado no estado do Rio de Janeiro, pelo Órgão Estadual do Meio Ambiente, INEA, que publicou em 2010 o Roteiro Metodológico para Elaboração de PM: Parques Estaduais, Reservas Biológicas e Estações Ecológicas, e dois anos depois publicou o Roteiro Metodológico Estadual para Elaboração de PM de RPPN.

Neste contexto, destacam-se os roteiros do IBAMA (2002), do INEA (2010) e do ICMBio (2018), que estabelecem os seguintes objetivos para os PM: (i) Propiciar o cumprimento dos objetivos da UC, conforme estabelecido em sua categoria e em sua criação; (ii) Estabelecer os objetivos específicos de manejo, orientando a gestão da UC; (iii) Instituir diretrizes para a implementação da UC; (iv) Orientar a aplicação dos recursos financeiros destinados à UC; (v) Elaborar ações específicas para o manejo da UC; (vi) Proporcionar o manejo da UC, baseado no conhecimento disponível e/ou gerado; (vii) Estabelecer a diferenciação do uso, mediante zoneamento, implementando a efetiva gradação de uso, objetivando a proteção de seus recursos; (viii) Integrar a UC no contexto do SNUC, frente aos atributos de valorização dos seus recursos como: biomas, convenções, certificações internacionais e projetos com recursos do exterior; (ix) Estabelecer, quando couber, normas e ações específicas visando compatibilizar a presença das populações residentes com os objetivos da Unidade, até que seja possível sua indenização ou compensação e sua realocação, respeitando-se a legislação estadual vigente; (x) Estabelecer normas específicas regulamentando a ocupação e o uso dos recursos da Zona de Amortecimento e dos Corredores Ecológicos, visando à proteção da UC; (xi) Fornecer um meio de comunicar aos diferentes públicos os elementos mais importantes acerca da UC; (xii) Promover a integração socioeconômica das comunidades do entorno com a UC; e (xii) Potencializar a participação social no Planejamento e Gestão da Unidade.

A partir dos roteiros analisados, pode-se dividir o PM em duas abordagens: Diagnóstico e Planejamento. No Diagnóstico, são apresentados todos os dados primários e secundários obtidos da UC para embasar a elaboração do Planejamento. Nesta etapa são descritas as informações gerais da UC, caracterização ambiental e institucional, sua contextualização e análise regional. Para o Planejamento são descritos os procedimentos e ações para implementação 
da UC. Nesta etapa são apresentados o planejamento, projetos específicos e metodologia de monitoramento e avaliação (IBAMA, 2002; INEA, 2010).

Para fins de exemplificação foi adotada a estrutura de PM constante do documento elaborado pelo INEA (2010), na qual o plano é dividido em seis módulos: 1. Informações gerais sobre a UC; 2. Contextualização e análise regional; 3. Análise da UC e entorno; 4. Planejamento; 5. Projetos específicos; 6. Monitoramento e avaliação. No módulo 4 podem ser incluídas normas gerais de uso público para tratar de condutas de segurança e saúde dos visitantes que, por desdobramento, para nortear os planos setoriais sobre o tema (v. g. Planos de Uso Público). As diretrizes de segurança sanitária estão incluídas no escopo dos componentes dinâmicos, conforme elementos do PM previstos pelo ICMBio (2018). Isso porque, acompanha-se o entendimento de que, mesmo após passadas as exigências de distanciamento social, os gastos dos (eco)turistas estarão condicionados à "confiança na segurança sanitária do destino" (FGV, 2020, p. 7). Portanto, diante da sua natureza e previsão legal, espera-se que o PM e o Plano de Uso Público (PUP) definam diretrizes suficientes para estabelecer essa relação de confiança com a comunidade no tocante à segurança sanitária da UC. A proposta de ampliação do escopo do PM e do PUP não desconhece as dificuldades institucionais e orçamentárias apontadas anteriormente e presentes nas pesquisas de autores como Lima et al. (2005), Medeiros e Pereira (2011), Mello (2008) e Pena (2018).

Complementarmente ao PM, existem dois documentos do ICMBio específicos para o uso público. As 'Orientações metodológicas para elaboração de planos de uso público em unidades de conservação federais' (CREMA; FARIA, 2019) e o 'Roteiro metodológico para manejo de impactos da visitação com Enfoque na Experiência do Visitante e na Proteção dos Recursos Naturais e Culturais' (ICMBio, 2011).

Os planos de uso público surgem como resultado de ações voltadas para dar eficiência ao PM. Assim, os planos específicos, como plano de uso público (PUP), "definem as orientações técnicas ou normas de manejo para temas específicos como visitação, proteção, pesquisa etc." (CREMA; FARIA, 2019, p. 7).

O uso público e o manejo da visitação, de forma geral, são documentos técnicos que concorrem para um objetivo comum de:

ampliar a implementação das UC para a visitação, consolidar o uso público como ferramenta de conservação e maximizar os impactos positivos do turismo, em especial a geração de negócios, o fortalecimento da aproximação com a sociedade e 0 desenvolvimento regional (CREMA; FARIA, 2019, p. 7).

No Quadro 2 estão propostas diretrizes adicionais ao conteúdo do PUP para adequação às condições de visitação pós-pandemia: 
Quadro 2: Adequações propostas ao conteúdo do PUP.

Table 2: Proposed adaptations to the content of the PUP.

\begin{tabular}{|c|c|}
\hline Orientações para PUP & Adequação - COVID-19 \\
\hline \multicolumn{2}{|l|}{ I. Contexto geral do uso público: } \\
\hline $\begin{array}{l}\text { - Atos legais norteadores: decreto de criação, } \\
\text { diretrizes de uso público, plano de manejo, etc.; }\end{array}$ & $\begin{array}{l}\text { - Verificar atos legais federais, estaduais e } \\
\text { municipais de prevenção, controle e } \\
\text { mitigação dos riscos de transmissão da } \\
\text { doença }\end{array}$ \\
\hline - Histórico e contexto da UC. & $\begin{array}{l}\text { - Incluir análise das condições de } \\
\text { saneamento intra e no entorno da UC }\end{array}$ \\
\hline \multicolumn{2}{|l|}{ II. Componentes Estratégicos: } \\
\hline - Visão de futuro da visitação; & $\begin{array}{l}\text { - Inserir estudos sobre demanda de visitação } \\
\text { pós-pandemia e alternativas virtuais }\end{array}$ \\
\hline $\begin{array}{l}\text { - Desafios e oportunidades para a visitação da } \\
\text { UC; }\end{array}$ & $\begin{array}{l}\text { - Discutir possibilidades virtuais e desafios } \\
\text { relacionados às condições de infraestrutura - } \\
\text { saneamento e higiene - para visitantes }\end{array}$ \\
\hline \multicolumn{2}{|l|}{ III. Diretrizes para implantação do UP: } \\
\hline $\begin{array}{l}\text { - Priorização de áreas de visitação e atividades } \\
\text { recreativas; }\end{array}$ & - Adequar de forma a evitar aglomerações \\
\hline \multicolumn{2}{|l|}{$\begin{array}{l}\text { Diretrizes, orientações e ações para a } \\
\text { implantação e operação do uso público na UC: } \\
\text { atividades, atrativos, infraestrutura, parceria, } \\
\text { voluntariado em uso público, etc; }\end{array}$} \\
\hline \multicolumn{2}{|l|}{$\begin{array}{l}\text { Monitoramento do número de visitas (IN } \mathrm{n}^{0} \\
5 / 2018 \text { ) }\end{array}$} \\
\hline \multicolumn{2}{|l|}{ IV. Proposições complementares: } \\
\hline 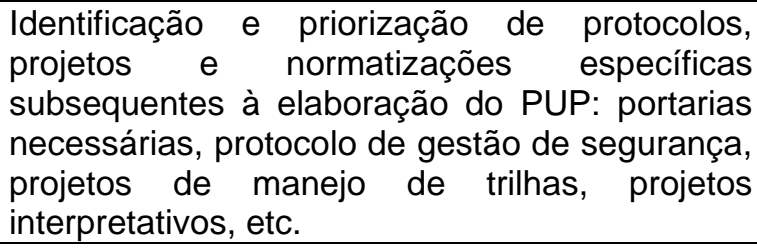 & - Incluir protocolos de segurança sanitária \\
\hline
\end{tabular}

Fonte: Elaborado pelos autores a partir de Crema e Faria (2019).

Source: Elaborated by the authors from Crema e Faria (2019)

No Quadro 2, estão apresentadas propostas de complementação às orientações para elaboração do PUP elaboradas com base nas circunstâncias identificadas no âmbito da transmissão da COVID-19. Para tanto, com base no manejo de impactos de visitação (ICMBio, 2011) as ações propostas devem ser precedidas de levantamento bibliográfico e documental específico sobre a COVID19. O estabelecimento do número balizador da visitação (NBV) por atividade e área específica na UC também deverá ser adequado ao conhecimento disponível sobre a transmissão pessoa a pessoa da COVID-19. O padrão indicado de uma pessoa por $2 \mathrm{~m}^{2}$ em trilhas (ICMBio, 2011) parece estar compatível com protocolos de segurança para COVID-19.

Dessa forma, compreende-se que outros indicadores de manejo poderão contribuir para a definição dos critérios de segurança para a COVID-19 e doenças semelhantes. Para um protocolo de segurança sanitária, a partir da epidemiologia da COVID-19, podem ser utilizados os seguintes indicadores de manejo de visitação estabelecidos pelo ICMBio (2011): i. número de pessoas simultaneamente em um mesmo atrativo; ii. número de grupos acampados em um mesmo período; iii. número de veículos em uma área de visitação; iv. tempo de espera em estabelecimentos de alimentação; v. tempo de espera para ver ou entrar em um atrativo; vi. número de grandes grupos (mais de 10 pessoas) em trilhas; vii. número de fezes ou de papel higiênico visíveis da trilha. 
Os indicadores selecionados possuem relação com a aglomeração de visitantes, tempo potencial de exposição e aspectos de higiene nos parques. Uma vez que eles já estão previstos, não há acréscimo na demanda operacional da UC.

Destarte, compreende-se que, apesar dos obstáculos orçamentários e técnicos, os órgãos ambientais elaboram roteiros metodológicos para elaboração de PM, PUP e manejo de impactos da visitação e que todos esses documentos necessitam de adequações ao novo contexto de pandemia para minimizar os riscos de transmissão da COVID-19 e de outras doenças com epidemiologia semelhante. A alteração no PM não tem caráter imediato e poderá seguir o processo de revisão previsto legalmente. O PUP, por sua própria natureza mais objetiva e célere, pode dar às UCs uma diretriz de segurança sanitária mais imediata e, assim, atender rapidamente a demanda potencial dos visitantes por este tipo de protocolo.

Assim, parecem viáveis, sem com isso sinalizar que investimentos na gestão das UCs sejam dispensáveis, ações frente à COVID-19, ao alerta quanto à emergência de novas pandemias por coronavírus e ao possível surgimento de novas demandas de segurança na visitação por visitantes e/ou organismos internacionais. Esses três fatores alteram diretamente a dinâmica no contexto da visitação e exigem um investimento direto no planejamento, na gestão e na capacitação dos agentes públicos. Logo, tanto os roteiros metodológicos, como os PM e os PUP, requerem uma releitura diante do cenário global que exige um novo contrato social voltado para estabelecimento de normas para garantir a saúde coletiva dos (eco)turistas.

\section{Diretrizes gerais para o Ecoturismo pós-pandemia}

Diante da constatação de que para o estabelecimento e a garantia de eficácia de novos padrões de sustentabilidade para a atividade turística são necessárias "vontade e consenso político" (FLETCHER et al., 2020), a título de contribuição para o debate teórico e para a elaboração de políticas públicas e de diretrizes de manejo, nessa seção estão elencadas propostas gerais e específicas para o ecoturismo no Brasil.

No campo da formação dos profissionais e gestores de (eco)turismo importa assinalar a proposta de revisão dos currículos para incluir o desenvolvimento de habilidades referentes ao pensamento da complexidade e de economias póscapitalistas (IOANNIDES; GYIMÓTHY, 2020), bem como, para o Brasil e América Latina, a discussão acerca da Teoria Decolonial e Economia Circular.

De maneira geral, a partir dos resultados da pesquisa de Pena (2018), realizada junto a gestores de UCs, e da literatura consultada, particularmente Fletcher et al. (2020), Everingham e Chassagne (2020) e FGV (2020), foram elencadas doze diretrizes com vistas a contribuir para o ecoturismo em UCs urbanas no Brasil:

i.Promover o (eco)turismo doméstico e assegurar o acesso de todas as camadas da população às UCs e, em especial, aos parques urbanos;

ii.Definir obrigações sociais e ambientais rigorosas para empresas transnacionais de turismo, de forma a evitar impactos em decorrência da busca por recuperação do lucro durante o período de suspensão das atividades; 
iii.Financiar pesquisas, por meio editais de fomento, com a finalidade de produzir evidências científicas voltadas para indução de políticas de (eco)turismo comunitário em parques urbanos;

iv.Criar fundo para direcionamento de recursos para iniciativas de (eco)turismo comunitário, privilegiando propostas em áreas de vulnerabilidade social no entorno de parques urbanos;

v.Ampliar os investimentos na gestão de UCs, particularmente em equipamentos de tecnologia, ampliação do corpo técnico e treinamento de servidores públicos para fornecer a experiência de visitação remota;

vi.Promover diagnóstico regional e local das potencialidades para 0 ecoturismo, preferencialmente em parceria com instituições de ensino e pesquisa;

vii.Suspender os atos normativos que estabelecem a reabertura de parques para visitação até que haja um planejamento específico, baseado nas evidências científicas mais atuais e na confirmação de que o pico da epidemia já foi ultrapassado;

viii.Criar prioritariamente, de acordo com o diagnóstico (item iii), linhas e incentivos de crédito específicos para o desenvolvimento do turismo comunitário com protagonismo dos residentes de bairros periféricos e favelas do entorno de parques urbanos;

ix.Diferir a carga tributária para pequenos e médios empreendedores locais de natureza comunitária;

x.Criar espaços e estimular iniciativas participativas nos governos locais;

xi.Implementar regulamentação para a reorganização de jornadas de trabalho e apoiar ações e iniciativas locais, com vistas a reduzir o número de desempregados no setor;

xii.Investir em infraestrutura de saneamento dentro de parques urbanos e nos bairros e favelas do entorno.

A partir de medidas pensadas para controlar o surto de COVID-19 (ROTHAN; BYRAREDDY, 2020) podem ser elencadas diretrizes gerais de saúde a serem previstas no PM ou nos PUP das UCs, tais como: i. realizar rotinas de visitação específicas voltadas para reduzir a transmissão de pessoa a pessoa em populações suscetíveis, como crianças e idosos; ii. fornecer reagentes de descontaminação para a limpeza das mãos em diferentes pontos de circulação dos visitantes; iii. manter rigoroso protocolo de higienização nos sanitários, incluída a vestimenta adequada dos profissionais de limpeza; iv. estabelecer normas e limites de visitação da UC, por trilha e/ou atrativo, assegurando distanciamento, uso de máscaras e outras medidas de prevenção.

Enfim, procurou-se contribuir com os resultados e a discussão apresentados para este bojo de iniciativas e de esforços teórico-metodológicos necessários para refletir crítica e propositivamente para o aprimoramento das políticas públicas de (eco)turismo e de gestão de UCs no Brasil e, particularmente, de parques urbanos. 


\section{Considerações finais}

A falta de recursos humanos e financeiros são causas estruturantes para uma gestão deficitária das UCs brasileiras. A postura do Executivo Federal (gestão 20192022) indica que o direcionamento orçamentário para contratação e capacitação de servidores para o ICMBio, instalação de infraestrutura física e tecnológica para visitantes e servidores e a promoção do ecoturismo com segurança sanitária ocorrerá somente mediante provocação e forte mobilização da sociedade. De forma semelhante, a crise econômica no Rio de Janeiro, agravada pela pandemia da COVID-19, contribuirá para a manutenção de investimentos insuficientes para promover o ecoturismo nas UCs estaduais.

O papel de pesquisadoras, pesquisadores, associações profissionais, instituições de ensino e pesquisa, coletivos sociais etc. é promover o diálogo, a divulgação de evidências científicas, métodos e técnicas para alimentar a revisão das políticas de gestão das UCs.

No caso de parques urbanos, como no município do Rio de Janeiro, a situação do ecoturismo pós-pandemia é agravada pela condição precária de acesso a água e esgotamento sanitário de favelas e bairros de menor renda no entorno do PNT e PEPB. A recessão econômica e o desemprego serão mais agudos nessas localidades e, portanto, demandarão a promoção de políticas públicas emergenciais.

Daí a importância de discutir o ecoturismo também como uma alternativa econômica nos parques urbanos e direcionar esforços para o turismo comunitário, no qual as comunidades do entorno serão protagonistas e principais beneficiários dos benefícios econômicos da visitação.

Por fim, a presente contribuição vai ao encontro de um conjunto de ações, reflexões e iniciativas teóricas e metodológicas que visam garantir segurança sanitárias nas UCs brasileiras, produzir e disseminar evidências científicas sobre iniciativas locais de ecoturismo, uso público e saneamento em unidades de conservação, contribuir para a elaboração de políticas públicas (ambientais, sociais e de saneamento), desenvolver o turismo comunitário em parques urbanos, reduzir as desigualdades sociais por meio da integração socioeconômica das comunidades do entorno e estimular uma reflexão crítica acerca do potencial do ecoturismo como alternativa econômica para comunidades em situação de vulnerabilidade social e ambiental.

\section{Referências}

ABREU, M. R. P.; TEJEDA, J. J. G.; GUACH, R. A. D. Características clínicoepidemiológicas de la COVID-19. Revista Habanera de Ciencias Médicas, v. 19, n. 2, e_3254, 2020.

ACOSTA, A.. Extrativismo e neoextrativismo: duas faces da mesma maldição. In: DILGER, G.; LANG, M.; PEREIRA FILHO, J. (Orgs.). Descolonizar o imaginário: debates sobre o pós-extrativismo e alternativas ao desenvolvimento. São Paulo: Fundação Rosa Luxemburgo, 2016. pp. 46-85.

ARAGÃO, A. Dimensões europeias do princípio da precaução. Revista da Faculdade de Direito da Universidade do Porto, número especial, p. 1-37, 2010. 
ARAGÃO, A. Aplicação nacional do princípio da precaução. In: ASSOCIAÇÃO DOS MAGISTRADOS DA JURISDIÇÃO ADMINISTRATIVA E FISCAL DE PORTUGAL. Colóquios 2011-2012. Lisboa: Associação dos Magistrados da Jurisdição Administrativa e Fiscal de Portugal, 2013. p. 159-185. Disponível em: $<$ http://bit.ly/1BpSxzc $>$. Acesso em: 19 fev. 2015.

BARRETO, M. L. et al. O que é urgente e necessário para subsidiar as políticas de enfrentamento da pandemia de COVID-19 no Brasil? Revista Brasileira de Epidemiologia, v. 23, p. 1-4, 2020.

BOTELHO, E. S.; RODRIGUES, C. G. O. Inserção das iniciativas de base comunitária no desenvolvimento do turismo em parques nacionais. Caderno Virtual de Turismo, v. 16, n. 2, p. 280-295, 2016.

BRASIL. Lei no 9.985, de 18 de julho de 2000. Regulamenta o art. 225, § 1o, incisos I, II, III e VII da Constituição Federal, institui o Sistema Nacional de Unidades de Conservação da Natureza e dá outras providências. Diário Oficial, Brasília, DF, 19 jul. 2000.

CAMPOS, G. W. S. O pesadelo macabro da Covid-19 no Brasil: entre negacionismos e desvarios. Trabalho, Educação e Saúde, v. 18, n. 3, p. 1-5, 2020.

CARSON, R. Primavera silenciosa. São Paulo: Gaia, 2010.

CARVALHO, D. W. Dano ambiental futuro: a responsabilização civil pelo risco ambiental. Rio de Janeiro: Forense Universitária, 2008.

CREMA, A.; FARIA, P. E. P. Orientações metodológicas para elaboração de planos de uso público em unidades de conservação federais. Brasília: ICMBio, 2019.

EVERINGHAM, P.; CHASSAGNE, N. Post COVID-19 ecological and social reset: moving away from capitalist growth models towards tourism as Buen Vivir. Tourism Geographies, $12 \quad$ maio 2020.2 Disponível em: $<$ https://doi.org/10.1080/14616688.2020.1762119 $>$. Acesso em: 11 jun. 2020.

FERNANDEZ, A. C. F. Um Rio de florestas: uma reflexão sobre o sentido da criação dos parques na cidade do Rio de Janeiro. Estudos Históricos, v. 24, n. 47, p. 141161, 2011.

FLETCHER, R.; MAS, I. M.; BLÁZQUEZ-SALOM, M.; BLANCO-ROMERO, A. Tourism, Degrowth, and the COVID-19 Crisis. Political Ecology Network, 24 mar. 2020. Disponível em: <https://politicalecologynetwork.org/2020/03/24/tourismdegrowth-and-the-covid-19-crisis/>. Acesso em: 11 jun. 2020.

FUNCIONAL HEALTH TECH. Funcional Health Tech lança ferramenta Open Source para pesquisas e análises de dados colaborativas sobre o novo coronavírus. Disponível em: <https://github.com/funcional-health-analytics/covid19analytics>. Acesso em: 23 jun. 2020.

FUNDAÇÃO GETÚLIO VARGAS. Impacto Econômico do COVID-19: Propostas para o Turismo Brasileiro. Rio de Janeiro: FGV, 2020. Disponível em: $<$ https://fgvprojetos.fgv.br/artigos/1a-edicao-impacto-economico-do-covid-19propostas-para-o-turismo-brasileiro-abril-2020>. Acesso em: 11 jun. 2020.

GIL, A. C. Como elaborar projetos de pesquisa. São Paulo: Atlas, 2002. 
GUDYNAS, E. Transições ao pós-extrativismo: sentidos, opções e âmbitos. In: DILGER, G.; LANG, M.; PEREIRA FILHO, J. (Orgs.). Descolonizar o imaginário: debates sobre o pós-extrativismo e alternativas ao desenvolvimento. São Paulo: Fundação Rosa Luxemburgo, 2016. pp. 176-212.

HARVEY, D. Política anticapitalista em tempos de COVID-19. In: HARVEY, D.; ŽIŽEK, S.; BADIOU, A.; DAVIS, M.; BIHR, A.; ZIBECHI, R. (Orgs.). Coronavírus e a luta de classes. Brasil: Terra sem Amos, 2020. pp. 13-23.

IBAMA - INSTITUTO BRASILEIRO DO MEIO AMBIENTE E DOS RECURSOS NATURAIS RENOVÁVEIS. Roteiro Metodológico para Elaboração de Plano de Manejo: Parque Nacional, Reserva Biológica e Estação Ecológica. Brasília: IBAMA, 2002. 136p.

IBAMA/WWF - INSTITUTO BRASILEIRO DO MEIO AMBIENTE E DOS RECURSOS NATURAIS RENOVÁVEIS/WORLD WIDE FUND FOR NATURE. Efetividade de gestão das unidades de conservação federais do Brasil. Brasília: IBAMA, 2007. $96 \mathrm{p}$.

ICMBIO - INSTITUTO CHICO MENDES DE CONSERVAÇÃO DA BIODIVERSIDADE. Visitação em Parques Nacionais bate novo recorde em 2018. Brasília: ICMBio, 2019. Disponível em: <https://www.icmbio.gov.br/>. Acesso em: 11 jun. 2020.

ICMBIO - INSTITUTO CHICO MENDES DE CONSERVAÇÃO DA BIODIVERSIDADE. Roteiro metodológico para elaboração e revisão de planos de manejo das unidades de conservação federais. Brasília: ICMBio, 2018. Disponível em: <https://www.icmbio.gov.br/portal/unidadesdeconservacao/roteirosmetodologicos >. Acesso em: 11 jun. 2020.

ICMBIO - INSTITUTO CHICO MENDES DE CONSERVAÇÃO DA BIODIVERSIDADE. Roteiro metodológico para manejo de impactos da visitação com Enfoque na Experiência do Visitante e na Proteção dos Recursos Naturais e Culturais. Brasília: ICMBio, 2011.

ICMBIO - INSTITUTO CHICO MENDES DE CONSERVAÇÃO DA BIODIVERSIDADE. Plano de Manejo do Parque Nacional da Tijuca. Rio de Janeiro: ICMBio, 2008.

INEA - INSTITUTO ESTADUAL DO AMBIENTE. Roteiro Metodológico para Elaboração de Planos de Manejo Parques Estaduais, Reservas Biológicas, Estações Ecológicas. Rio de Janeiro: INEA, 2010. 115p.

IOANNIDES, D.; GYIMÓTHY, S. The COVID-19 crisis as an opportunity for escaping the unsustainable global tourism path. Tourism Geographies, 12 maio 2020. Disponível em: <https://doi.org/10.1080/14616688.2020.1763445>. Acesso em: 11 jun 2020.

LANG, M. Alternativas ao desenvolvimento. In: DILGER, G.; LANG, M.; PEREIRA FILHO, J. (Orgs.). Descolonizar o imaginário: debates sobre o pós-extrativismo e alternativas ao desenvolvimento. São Paulo: Fundação Rosa Luxemburgo, 2016. pp. 24-44.

LEMOS DE SÁ, R. M.; FERREIRA, L. M. Áreas protegidas ou espaços ameaçados: o grau de implementação e a vulnerabilidade das Unidades de Conservação federais brasileiras de uso indireto. Brasília: WWF-Brasil: Série Técnica, v. 3, 32 p. 2000. 
LIMA, G.; RIBEIRO, G.; GONÇALVES, W. Avaliação da Efetividade de Manejo das Unidades de Conservação de Proteção Integral em Minas Gerais. Revista Árvore, Viçosa, v. 29, n. 4, p. 647-653, 2005.

LIMONGI, J.; DE OLIVEIRA, S. COVID-19 e a abordagem One Health (Saúde Única): uma revisão sistemática. Vigilância Sanitária em Debate: Sociedade, Ciência \& Tecnologia, v. 8, p. 1-11, 2020.

MEDEIROS, R.; PEREIRA, G. Evolução e Implementação dos Planos de Manejo em Parques Nacionais no Estado do Rio de Janeiro. Revista Árvore, Viçosa, v. 35, n. 2, p. 279-288, 2011.

MELLO, R. Plano de Manejo: Uma análise crítica do processo de planejamento das unidades de conservação federais. 2008. Dissertação (Mestrado em Ciência Ambiental) - Universidade Federal Fluminense, Niterói, 2008.

MELLO, R. B. Nova Abordagem para Elaboração de Planos de Manejo do ICMBio. In: ENCONTRO DE PARQUES DE MONTANHA, 3, Rio de Janeiro. 2017. Disponível em: <http://www.cbme.org.br/novo/mesas-e-apresentacoes/>. Acesso em: 07 out. 2018.

PEIXOTO, S.; IRVING, M. A. O conceito de parque urbano da paz. In: CORRÊA, A. M.; MOUTINHO-DA-COSTA, L.; BARROS, J. F. (Orgs.). A floresta: educação, cultura e justiça ambiental. Rio de Janeiro: Garamond, 2013. p. 25-33.

PENA, R. C. Monitoramento e avaliação de planos de manejo: um estudo de caso do Monumento Natural dos Morros do Pão de Açúcar e da Urca. 2018. Dissertação (Mestrado em Ecoturismo e Conservação) - Universidade Federal do Estado do Rio de Janeiro, Rio de Janeiro, 2018.

QUIJANO, A. Colonialidad del poder y clasificación social. Journal of World Systems Research, v. 6, n. 2, p. 342-388, 2000.

RICARD, J.; MEDEIROS, J. Using misinformation as a political weapon: COVID-19 and Bolsonaro in Brazil. The Harvard Kennedy School (HKS) Misinformation Review, v. 1, n. 2, p. 1-6, 2020.

ROMAGOSA, F. (2020): The COVID-19 crisis: opportunities for sustainable and proximity tourism. Tourism Geographies, 2020. Disponível em: $<$ https://doi.org/10.1080/14616688.2020.1763447>. Acesso em: 11 jun. 2020.

ROTHAN, H. A.; BYRAREDDY, S. N. The epidemiology and pathogenesis of coronavirus disease (COVID-19) outbreak. Journal of Autoimmunity, v. 109, 2020.

SCHIAVETTI, A.; MAGRO, T. C.; SILVA, M. Implementação das unidades de conservação do corredor central da Mata Atlântica no estado da Bahia: desafios e limites. Rev. Árvore, v. 36, p. 611-623, 2012.

SOUZA, D. O. A pandemia de COVID-19 para além das Ciências da Saúde: reflexões sobre sua determinação social. Ciência \& Saúde Coletiva, v. 25, supl.1, p. 2479-2488, 2020.

VARELlA, M. D.; PLATIAU, A. F. B. (Orgs.). Princípio da precaução. Belo Horizonte: Del Rey, 2004.

VILANI, R. M. Ecoturismo: a conservação da natureza como alternativa aos Grandes Projetos de Investimento (GPIs) no Rio de Janeiro. Revista Brasileira de Ecoturismo, v. 11, n. 4, p. 609-633, 2018. 
VILANI, R. M.; COELHO, B. S. Ecoturismo no Parque Estadual da Pedra Branca, Rio de Janeiro, Brasil. Revista Turismo \& Desenvolvimento, n. 27-28, p. 535-546, 2017.

WORLD HEALTH ORGANIZATION. Coronavirus disease (COVID-19) pandemic. Disponível em: <https://www.who.int/emergencies/diseases/novel-coronavirus2019>. Acesso em: 09 jun. 2020.

ŽlŽEK, S.. Um golpe como o de "Kill Bill" no capitalismo. In: HARVEY, D.; ŽlŽEK, S.; BADIOU, A.; DAVIS, M.; BIHR, A.; ZIBECHI, R. (Orgs.). Coronavírus e a luta de classes. Brasil: Terra sem Amos, 2020. pp. 43-47.

\section{Notas:}

${ }^{1}$ Para Fletcher et al. (2020) overtourism significa "a presença de um número crescente de turistas em destinos populares em todo o mundo, levando a conflitos e reclamações por parte dos residentes, preocupados com o fato de que esse afluxo deixa seus lares inabitáveis" (tradução nossa).

Rodrigo Machado Vilani: Universidade Federal do Estado do Rio de Janeiro, Rio de Janeiro, RJ, Brasil.

E-mail: rodrigo.vilani@unirio.br

Link para o currículo Lattes: http://lattes.cnpq.br/9026743148214335

Roberta Campelo Pena: Universidade Federal do Estado do Rio de Janeiro, Rio de Janeiro, RJ, Brasil.

E-mail: robertacpena@gmail.com

Link para o currículo Lattes: http://lattes.cnpq.br/4291893812655630

Bruno Francisco Teixeira Simões: Universidade Federal do Estado do Rio de Janeiro, Rio de Janeiro, RJ, Brasil.

E-mail: bruno.simoes@uniriotec.br

Link para o currículo Lattes: http://lattes.cnpq.br/0985291000032685

Data de submissão: 29 de junho de 2020.

Data de recebimento de correções: 07 de julho de 2020

Data do aceite: 07 de julho de 2020

Avaliado anonimamente 